\title{
The Impact of Agricultural Technologies on Poverty and Vulnerability of Smallholders in Ethiopia: A Panel Data Analysis
}

\author{
Wubneshe Dessalegn Biru' ${ }^{1}$ (D) Manfred Zeller ${ }^{1}$ (D) Tim K. $\operatorname{Loos}^{1}$ (D)
}

Accepted: 25 July 2019 / Published online: 2 August 2019

(C) The Author(s) 2019, corrected publication 2019

\begin{abstract}
Many studies evaluating the impact of adoption on welfare focused on adoption of a single technology giving little attention on the complementarity/substitutability among agricultural technologies. Yet, smallholders commonly adopt several complementary technologies at a time and their adoption decision is best characterized by multivariate models. This paper, therefore, examines the impact of multiple complementary technologies adoption on consumption, poverty and vulnerability of smallholders in Ethiopia. The study used a balanced panel data obtained from a survey of 390 farm households collected in 2012, 2014 and 2016. A two stage multinomial endogenous switching regression model combined with the Mundlak approach and balanced panel data is employed to account for unobserved heterogeneity for the adoption decision and differences in household and farm characteristics. An ordered probit model is used to analyze the impact on poverty and vulnerability. We find that the adoption of improved technologies increases consumption expenditure significantly and the greatest impact is attained when farmers combine multiple complementary technologies. Similarly, the likelihood of households to remain poor or vulnerable decreased with the adoption of different complementary technologies. We therefore conclude that the adoption of multiple complementary technologies has substantial dynamic benefits that improve the welfare of smallholders in the study area, and given the observed low level of adoption rates, we suggest that much more intervention is warranted, with a special focus on poorer and vulnerable households, to ensure smallholders get support to improve their input use.
\end{abstract}

Electronic supplementary material The online version of this article (https://doi.org/10.1007/s1120 5-019-02166-0) contains supplementary material, which is available to authorized users.

Wubneshe Dessalegn Biru

wubneshed.biru@uni-hohenheim.de

Manfred Zeller

zellerm@uni-hohenheim.de

Tim K. Loos

tim.loos@uni-hohenheim.de

1 Rural Development Theory and Policy (490a), Institute of Agricultural Sciences in the Tropics (Hans-Ruthenberg-Institute) (490), University of Hohenheim, Stuttgart, Germany 
Keywords Vulnerability $\cdot$ Poverty $\cdot$ Technology adoption $\cdot$ Ethiopia $\cdot$ Panel data

\section{Introduction}

Sub-Saharan Africa (SSA) has the highest number of people living in extreme poverty, comprising 413.3 million people in 2015 (Beegle et al. 2016). The number has grown substantially since the 1990 s and about $88 \%$ of the world's poorest are expected to live in Africa by 2030 (World Bank 2015). In Ethiopia about 33\% of the rural population lives below the national poverty line and an additional $14 \%$ of non-poor households are estimated to be vulnerable to falling into poverty (World Bank 2015). Non-poor households are vulnerable to poverty because of their exposure to various types of shocks and their lack of coping mechanisms (Dercon 2004). As a result, improving agricultural productivity growth is considered key to alleviating poverty and vulnerability ${ }^{1}$ of smallholder farmers. This is because the majority of the rural population depends on rain-fed subsistence agriculture with limited use of improved agricultural technologies. Ethiopia's agricultural sector makes up the lion's share of the national economy, accounting for about 43\% of GDP, $90 \%$ of merchandise exports, and $96 \%$ of rural employment. Despite this importance, agricultural productivity in the country is low; it is constrained by recurrent droughts, erratic rainfall, declining soil fertility, missing or imperfect input and output markets as well as limited access to improved technologies (Abebe and Sewnet 2014; Asfaw et al. 2011; Misiko and Ramisch 2007; Morris and Doss 1999; Pender et al. 2006).

Since 1992, the government of Ethiopia has implemented Agricultural Development Led Industrialization (ADLI), an economic growth strategy, in response to the poverty and food security challenges of the country. As indicated by the Ministry of Finance and Economic Development (MoFED), the ADLI policy focuses mainly on strengthening the interdependence between agriculture and industry by increasing the productivity of smallholder farmers through better agronomic practices, research and extension, technology transfer, and rural infrastructure (MoFED 2003). Consequently, regional and national research institutes in the country have released a number of improved agricultural technologies in crops, livestock, and natural resource management practices over the past two decades. The intervention has enabled relatively higher proportions of farmers to adopt improved crop production technologies in some areas of the country (Doss et al. 2003; Mandefro et al. 2002; Tadesse and Degu 2002). Moreover, the recent Growth and Transformation Plans (GTP I and GTP II) of the country also gives special emphasis to the notion of resource management based agricultural systems at the policy level. However, the introduction and adoption of those technologies has had only partial success, as measured by observed rates of adoption in the country. For instance, Spielman et al. (Spielman 2011) reported that only 30-40\% of Ethiopian smallholders apply fertilizer in their field, and their application, which is only 37-40 kilograms per hectare, is usually far below the recommended rates. Using a nationally representative household data, Minot and Sawyer (2013) found a slightly higher rates of fertilizer use (56\%) among smallholders in Ethiopia both belg and meher seasons in the 2012 agricultural year. The same study further revealed a similar trend (56\%) on the use of purchased seed (even though it doesn't necessarily mean improved seed), and $31 \%$ of the farmers apply

${ }^{1}$ In this paper, vulnerability refers to "vulnerability to poverty". 
pesticide in the same agricultural year. Yu and Pratt (2014) reported that the adoption rate of the new technology packages released in Ethiopia increased from $42 \%$ in 2003 to $48.5 \%$ in 2006 then fell below $47 \%$ in 2007 . The adoption of soil and water conservation practice by smallholders also remains very low in the country due to inadequate information on the technical details of the technology, low short term benefits, decrease in total cultivable area and labor requirement (Wolka 2014; Asfaw and Neka 2017). Since, improved agricultural technologies play an important role in fighting poverty and vulnerability to poverty, it is important to assess to what extent their impact on the different wealth categories of smallholders.

The effectiveness of productivity enhancing technologies (PETs), such as chemical fertilizer and improved seed, depends on the type of soil and water availability (Kassie et al. 2013). With almost negligible use of irrigation and water harvesting technologies in the region, water scarcity is one of the major constraining factors of agricultural productivity in Ethiopia. Therefore, it is important to complement the PETs with improved soil and water conservation (SWC) practices, such as terracing. The SWC practices help smallholders protect against the high levels of soil depletion and erosion problems observed in the region (Mango et al. 2017). The SWC practices improve soil fertility and preserve water, which in turn increases the effectiveness of yield enhancing technologies and consequently increases crop productivity. Studies, such as Kassie et al. (2013), clearly show that soil conservation and water harvesting practices play a crucial role in sustaining crop yields by increasing soil moisture.

Several studies show a significant positive impact of improved agricultural practices on the welfare of smallholders (Abebe and Sewnet 2014; Ali and Abdulai 2010; Asfaw et al. 2012; Bezu et al. 2014; Kassie et al. 2018; Manda et al. 2016). According to Diao (2010), for instance, a $1 \%$ annual increase in Ethiopia's GDP driven by agricultural growth leads to a $1.78 \%$ reduction in the country's poverty headcount rate per year. A study by Janvry and Sadoulet (2002) showed that the adoption of agricultural technologies affect poverty and vulnerability to poverty directly or indirectly. The direct impact is through improving agricultural productivity, which lead to an increase in home-consumed food and marketable surplus, which in turn reduces the poverty and vulnerability of adopters. An indirect effect may be achieved through a reduction in food prices for non-adopters and net buyers of food. Enhancing agricultural productivity, particularly for important staple crops in the region such as teff, maize, wheat, and barley improves supply and reduces the staple food price, and in so doing helps to lift the poor above the poverty line (Christiaensen and Subbarao 2005; de Janvry and Sadoulet 2002; Diao 2010).

In this paper, we assess the impact of the adoption of PETs, including chemical fertilizer, improved seed variety, and pesticides, and SWC practices, including terracing and contour ploughing, on the consumption, poverty, and vulnerability of smallholders in Ethiopia. These technologies are popular practices in the study area (Di Falco and Bulte 2013). There is extensive literature assessing the impact of adopting a single technology on the welfare of farmers (see Asfaw et al. 2012; Becerril and Abdulai 2009; Bezu et al. 2014; Hailu et al. 2014; Kassie et al. 2018; Verkaart et al. 2017). In fact, agricultural technologies are mostly introduced and recommended to be used with other complementary inputs (Dercon et al. 2009; Howard et al. 2003; Spielman et al. 2010) and the maximum potential can only be reached when interrelated technologies and complementary practices are implemented simultaneously (Abdulai and Huffman 2014; Kassie et al. 2018). Few studies assessed the impact of adopting multiple technologies jointly on the welfare of farmers (Kassie et al. 2013; Teklewold et al. 2013). Of those few studies, even fewer analyzed the dynamic impact of the technology combinations. Hence, the main objective of this article 
is to estimate the impact of PETs and SWC measures and their possible combinations on changes in consumption, poverty and vulnerability to poverty over time.

This introduction is followed by a description of the conceptual framework and estimation strategy that form the theoretical and empirical basis for the econometric analyses. After describing the data and explanatory variables, the empirical results are discussed. Finally, conclusions and recommendations based on the major findings are presented.

\section{Conceptual Framework and Estimation Strategy}

An individual farmer in Ethiopia is both a food producer and a consumer, i.e., smallholders are involved in both production and consumption decisions. Smallholder farmers in Ethiopia, like any other rural households in developing countries, are faced with various constraints such as imperfect or missing input and credit markets, high transaction costs and unemployment. With the presence of such market failure in rural areas where farmers consume significant proportion of their outputs and supply significant proportion of factor input, assuming consumption and production decisions as independent is erroneous. Rural households are endowed with five different types of assets upon with which they build their livelihoods. These assets include physical, financial, natural, social and human capital. Households therefore employ the different combinations of the assets in order to maximize their utility. On the other hand, their livelihood strategies are influenced by external factors such as agro-climatic conditions, pests and diseases, policies, institutions, and processes that in turn influence the productivity of households. The introduction of agricultural technologies such as chemical fertilizer and improved seed variety or the promotion of improved SWC practices affect the farmers' perception, expectation and preference toward different varieties and inputs used in production. These in turn will condition their decisions in terms of investment, crops and varietals choice, and resource allocation to various inputs (Asfaw et al. 2011). Supposedly, this would affect household's level of consumption for food and essential non-food items, marketable surplus of different crop varieties, savings, and income generation activities. Therefore, household decisions and choice constitute their behavioral outcomes which will finally affect their consumption expenditure (welfare outcomes). Thus, by insuring food production against extreme weather events and household-level shocks, such as illness or the death of a family member, the adoption of improved PETs combined with SWC practices is crucial in improving the resilience of farmers and decrease vulnerability to poverty. In general household models are non-separable and that household resource allocation including off-farm labor supply is determined simultaneously rather than recursively (de Janvry et al. 1991).

$\mathrm{W}$ model the adoption decision behavior of farmers at time $t$ following Kassie et al. (2015) and Abdulai and Huffman (2014) where the adoption decision is modeled in a random utility framework. In this framework, smallholders are assumed to maximize their utility function subject to the different resource constraints. Given a set of agricultural technology choices, rural households face various constraints in their adoption decision process. In this paper, based on the aforementioned literatures, we assume that smallholder farmers adopt a technology set $m$ at time $t$ to maximize utility, max $u_{i t}=\mathrm{f}\left(x_{i t}\right)$ subject to the various adoption constraints, where $\mathrm{x}$ is the explanatory variables affecting the adoption decision of the farmer.

An individual farm household considers adopting a single improved technology or a set of improved technologies if the expected utility from adoption $\mathrm{E}\left(U_{i t A}\right)$ is higher 
than the expected utility from non-adoption $\mathrm{E}\left(U_{i t N}\right)$. Farmers are therefore assumed to choose the combination of technologies that provides maximum expected utility. In other words, the difference between the expected utility from adoption and the expected utility from non-adoption denoted as $Y^{*}$ such that a utility maximizing farm household $i$ will consider adopting a set of technology, if the expected utility obtained from adopting is greater than the expected utility from non-adoption $\left(Y^{*}=\mathrm{E}\left(U_{i t A}\right)-\mathrm{E}\left(U_{i t N}\right)>0\right)$. Since the utilities gained are unobservable, it can be expressed as the following latent variable model:

$$
Y_{i t m}^{*}=\beta X_{i t m}+\mu_{i} \quad \text { where } Y_{i t m}=\left\{\begin{array}{ll}
1 & \text { if } Y_{i m}^{*}>0 \\
0 & \text { otherwise }
\end{array} \quad m=1,2 \ldots M\right.
$$

where $Y$ is an observable categorical indicator variable that equals 1 if the farmer adopted a single technology or set of technologies and zero for non-adoption; $\beta$ is a vector of parameters to be estimated; $X$ is a vector of explanatory variables; and $\mu$ is the error term.

To evaluate the impact of adoption on welfare, in our case, the outcome variable of interest is per capita consumption expenditure in real terms, assumed to be a linear function of observed household and plot characteristics along with the technology adoption categorical variable. Using panel data, the outcome equation can be written as:

$$
\operatorname{lnc}_{i t}=\beta X_{i t}+\eta I_{i t}+\alpha_{i}+\varepsilon_{i t}
$$

where lnc $_{\text {it }}$ represents the logarithm of real per capita consumption at time $t$ and for the ith household; $\beta$ denotes vector of coefficients; $X_{i t}$ represents vector of explanatory variables for household $i$ at time $t$; $I$ in this case is a categorical variable $(I=1,2 \ldots . \mathrm{M}$ if the household adopted the technology set; $I=0$ if none of the technologies are adopted); $\eta=$ measures the effect of the technology; $\alpha_{i}=$ unobserved household specific fixed effects assumed to be fixed over time but vary across household $i$; $\varepsilon_{i t}$ is the error term. Therefore, for this model the effect of improved technology is the estimate of $\eta$. However, the categorical variable I cannot be treated as exogenous if the decision of an individual to adopt or not to adopt is based on individual self-selection (Maddala 1983; Wooldridge 2002). Therefore, evaluating impact of technology adoption is challenging, since the counterfactuals are unobserved, that is we do not observe what would have happened had the farmer did not adopt technologies leading to potential selection bias and unobserved heterogeneity (Heckman 1979). Thus, analyzing the impact of technologies on welfare requires controlling for unobserved heterogeneity and potential selection bias. Selection bias arises when technology adoption is voluntarily decided or some technologies are targeted to a given group of farmers. For instance, more relatively wealthy farmers could be those who adopt modern technologies; in this case, self-selectivity into technology adoption is the source of endogeneity (Hausman 1978). This problem can be commonly solved by using an instrumental variable regression model. Alternatively, with the availability of panel data, a panel data estimator solves the problem without instrumental variable. However, this can only be attained if the selection process is based on time constant unobserved heterogeneity (Maddala 1983; Wooldridge 2002). As explained, however, the selection process might be generated by time-varying unobserved heterogeneity that affects the outcomes (Wooldridge 2002). In such case, the availability of panel data alone is insufficient and the estimates of the fixed effects or random effects models are inappropriate. To solve this problem, we combine a panel data estimator with an endogenous switching regression (ESR) model that enables us to capture time-varying unobserved heterogeneity (Abdulai and Huffman 2014; Kassie et al. 2018). 


\subsection{Two-Stage Endogenous Switching Multinomial Logit Regression Model}

Following Kassie et al. (2018), we estimated a two-stage endogenous switching multinomial logit model (ESMNL). Assuming a technology set $m, m$ is equal to 1 if the household adopted a combination of technologies or only a single technology and 0 if otherwise; and the utility function that ranks the $i$ th household's preference for these improved technologies by $\mathrm{U}\left(L_{m i}, R_{m i}\right)$, utility depends on a vector of $L_{m}$ of moments that describe the distribution of technology set $m$, including adoption cost and a vector $R_{m}$ of other attributes associated with the technology (Di Falco et al. 2011; Kassie et al. 2018). The variables $L_{m}$ and $R_{m}$ are unobservable, but a linear relationship is postulated for the $i$ th household. The ESR model also allows the technology set choices (treatment variables) to interact with observable variables and unobserved heterogeneity. This means that the effect of technology choice is not limited to the intercept of the outcome equations, (see Zeng et al. 2015), but can also have a slope effect. ${ }^{2}$

We estimate the pooled OLS following Wooldridge (2002) and pooled selection models using the Mundlak (1978) approach. We included the means of the time-varying explanatory variables as additional explanatory variable in both the outcome and adoption equations so as to control for unobserved heterogeneity (Mundlak 1978). The Mundlak device combines the fixed-effects and random effects estimation approaches. By including, the mean of time-varying explanatory variables, we control for time-constant unobserved heterogeneity, as with fixed effects, while avoiding the problem of incidental parameters in nonlinear models such as the multinomial logit (MNL) model. Using the three round balanced data, we also run the random effects model using the Mundlak approach controlling for unobserved time-varying heterogeneity. The estimation of multinomial switching endogenous regression framework involves a two-step estimation procedure. In the first step, a MNL model accounting for unobserved individual heterogeneity is estimated to generate the inverse Mills ratio. For the MNL model, the IIA assumption is met (Dubin and Mcfadden 1984). Previous empirical studies evaluated impact of adoption using an endogenous switching regression include Di Falco et al. (2011), Teklewold et al. (2013), Abdulai and Huffman (2014) and Kassie et al. (2015, 2018).

The adoption of five technologies and their combinations involves 32 possible technology choice sets (including an "empty" set for non-adoption). We specified 32 equations for each technology choice set. However, we combined some of the technology choice sets because of insufficient observations for most of the practices and many of the potential combinations were not observed in our sample households. After the different tests, ${ }^{3}$ we finally reduced the number of outcome (consumption equations) to nine technology choice sets including the "empty set" for non-adoption.

The five technologies with their combinations considered here are: PETs include chemical fertilizer, improved seed variety, and pesticide and SWC measures include terracing and contour ploughing. These technologies are commonly practiced in the study area. As mentioned above, we base our analysis on the latent variable concept, where we assume that each time period the household chooses a technology set that maximizes the expected utility. Let a farm household choosing a technology set $\mathrm{m}$

\footnotetext{
${ }^{2}$ We used a chow test to see if the different combined practices have significantly different slopes.

${ }^{3}$ For the independence of the different technology combinations, we used the Stata user command mlogtest to test the possibility of combining related technologies in MNL model and the chow test commands to test for slope differences in the outcome equations.
} 
$(\mathrm{m}=0,1,2, \ldots, 6)$ and $\mathrm{j}=0$ denoting that none of the practices were adopted, while the remaining technology sets $(\mathrm{m}=1,2, \ldots, 6)$ contain at least one technology be represented by $\mathrm{u}_{m t}$. A farm household chooses a technology set $m$ if and only if its expected utility $\mathrm{u}_{m t}$ is greater than the expected utility $\left(\mathrm{u}_{k t}\right)$ that could be obtained from other technology sets including the non-adoption option, i.e., $\mathrm{u}_{m t}>\mathrm{u}_{k t}, m \neq k$.

Following Kassie et al. (2015), we specify the utility of adoption as a function of exogenous variables including household, plot characteristics averaged at household level as well as regional and time dummies. The probability that a farm household adopt technology set $\mathrm{m}$ time $\mathrm{t}$ conditional on $\mathrm{x}_{\mathrm{it}}$ can be represented as:

$$
\operatorname{prob}\left(\mathrm{j} \mid \mathrm{X}_{\mathrm{it}}, \mathrm{Z}_{\mathrm{i}}=\frac{\exp \left(\mathrm{a}_{\mathrm{i}}+\mathrm{X}_{\mathrm{it}} \beta_{\mathrm{m}}+\mathrm{Z}_{\mathrm{i}}\right)}{\sum_{\mathrm{k}=1}^{\mathrm{m}} \exp \left(\mathrm{a}_{\mathrm{k}}+\mathrm{X}_{\mathrm{it}} \beta_{\mathrm{k}}+\mathrm{Z}_{\mathrm{i}}\right)}\right), \quad \mathrm{m}=0,1,2 \ldots 6
$$

where i represents individual farmer; $m$ represents technology set and $t$ represents time period; $\mathrm{a}_{\mathrm{m}}$ is the specific constant term of technology set $\mathrm{m} ; X_{i t}$ represents matrix of observable explanatory variables that affects the probability of adoption, $Z_{i}$ denotes time constant unobserved heterogeneity term and $\beta_{m}$ represents unknown parameters to be estimated. As discussed above, the unobserved heterogeneity $\left(\mathrm{Z}_{i}\right)$ will be replaced by means of the time-varying explanatory variable $\left(\mathrm{X}_{i}\right)$, following the Mundlak approach. Equation (3) is estimated using MNL model based on household level balanced panel data. To implement the Mundlak approach, we include the means of all time-varying covariates. In the second stage ESR, the consumption function is estimated for adopters and non-adopters separately controlling for the endogenous nature of technology adoption decisions. The seven consumption expenditure equations are specified as follows:

$$
\left\{\begin{array}{l}
\text { Regime } 0: \ln _{\mathrm{it} 0}=\mathrm{V}_{\mathrm{it} 0} \beta_{0}+\lambda_{\mathrm{it} 0} \sigma_{0}+\mathrm{H}_{\mathrm{i} 0}+\varepsilon_{\mathrm{it} 0} \quad \text { if } m=0 \\
\cdot \\
\text { Regimem }: \ln _{\mathrm{itM}}=\mathrm{V}_{\mathrm{itM}} \beta_{\mathrm{M}}+\lambda_{\mathrm{itM}} \sigma_{\mathrm{M}}+\mathrm{H}_{\mathrm{iM}}+\varepsilon_{\mathrm{itM}} \quad \text { if } m=M, 1,2 \ldots \ldots 6
\end{array}\right.
$$

where $\mathrm{m}=0$ denotes that neither of the technologies nor their combinations were adopted and $\mathrm{m}=1, \ldots 6$ represents adoption of either technology or their combinations; $\ln C_{i t M}$ denotes the consumption expenditure for household $i$ at time $t$ with technology and $\ln _{\mathrm{it} 0}$ represent the consumption expenditure for household $i$ at time $t$ with no adoption. $V_{i t}$ denotes observable household, plot and village characteristics, including a time period dummy $(T)$, that influence consumption expenditure at time $t ; \beta$ and $\sigma$ are parameter to be estimated and the covariance between the error terms and adoption and outcome equations, respectively. $\mathrm{H}_{i}$ is the time invariant unobservable household heterogeneity; $\hat{\bar{\lambda}}$ is inverse Mills from Eq. (3) to capture time-varying individual effects (Dubin and Mcfadden 1984). As in the choice model, the time invariant unobserved variable $(\bar{H})$ is parameterized by the mean values of time-varying explanatory variables $\bar{Z}$ Time period and regional dummies are included in our estimation to capture temporal and spatial differences in agro-ecology, price and institutions. 


\subsection{Expected Actual and Counterfactual Outcomes}

The estimated treatment effects are of particular interest in this context, specifically the average treatment effect (ATE) and the average treatment effect for the treated (ATT). The ATE is defined as the effect of treatment on a person selected at random from the given population relative to the effect on that person had he or she not received the treatment. This is the difference between the treated and untreated state for a given person (Gregory 2015). After estimating the consumption equation, the next step is computing the expected and counterfactual outcomes. This is important to explicitly evaluate the causal effect of improved technology adoption. The actual expected outcomes that are observed in the data are computed as:

$$
\mathrm{E}\left(\ln \mathrm{C}_{\mathrm{itM}} \mid \mathrm{m}=\mathrm{M}\right)=\mathrm{V}_{\mathrm{itM}} \beta_{\mathrm{M}}+\lambda_{\mathrm{itM}} \sigma_{\mathrm{M}}+\hat{\mathrm{V}}_{\mathrm{iM}} \omega_{\mathrm{M}}
$$

On the other hand, the counterfactual expected value of consumption expenditure for household $\mathrm{i}$ with a technology set $\mathrm{m}$ that contains one or more improved technologies is given as follows:

$$
\mathrm{E}\left(\ln _{\mathrm{it} 0} \mid \mathrm{m}=\mathrm{M}\right)=\mathrm{V}_{\mathrm{itM}} \beta_{0}+\lambda_{\mathrm{itM}} \sigma_{0}+\hat{\mathrm{V}}_{\mathrm{iM}} \omega_{0}
$$

where the parameters $\beta_{0}, \sigma_{0}$ and $\omega_{0}$ are coefficients obtained from estimation of consumption expenditure without a technology set $(m=0)$ and other variables are as defined above. Taking the difference between Eqs. (5) and (6) gives the average effect of technology on adopters, often described in the literature as the average treatment effect on the treated (ATT). The ATT can be derived as:

$$
\begin{aligned}
\operatorname{ATT}_{\mathrm{ym}} & \left.=\mathrm{E}\left(\ln C_{i t 1} \mid \mathrm{m}=\mathrm{M}\right)-\mathrm{E}\left(\ln C_{\mathrm{it} 0} \mid \mathrm{m}=\mathrm{M}\right)\right) \\
& =\left(\beta_{\mathrm{m}}-\beta_{0}\right) \mathrm{V}_{\mathrm{itm}}+\left(\sigma_{\mathrm{M}}-\sigma_{0}\right) \lambda_{\mathrm{itM}}+\left(\omega_{\mathrm{M}}-\omega_{0}\right) \hat{\mathrm{V}}_{\mathrm{iM}}
\end{aligned}
$$

The first two terms of Eqs. (7) indicate consumption expenditure change due to the difference in returns to observed characteristics and time-invariant unobserved characteristics, respectively, and the last term attributes to changes in consumption because of time-varying unobserved heterogeneity difference.

The consumption expenditure calculation focuses on food expenditure and includes both own production and purchased food, purchased meals, and non-investment non-food items (Dercon et al. 2005). Taxes, rents, contributions to durable goods, and health and education expenditures are not included in the calculation. Furthermore, the real per capita consumption expenditure ${ }^{4}$ is deflated by the food price index using the 2012 prices as a base. The present analysis is performed on three rounds of balanced household panel datasets spaced 2 years apart.

\footnotetext{
4 The consumption data are based on summing the expenditures of all sources of food and non-food consumption, deflated by a consumer price index, using 2012 as the base. It is expressed in monthly per capita units in ETB. The national poverty line in 2011/2012 prices is $3781 \mathrm{ETB} /$ adult/year, thus the per capita monthly expenditure in this case is ETB 315.
} 


\subsection{Measure of Poverty and Vulnerability}

It is expected that the adoption of improved technologies and SWC contribute to poverty reduction through improving income and level of food security of smallholder farmers in most developing countries (Asfaw et al. 2012; Becerril and Abdulai 2009; de Janvry and Sadoulet 2002). Using per capita consumption expenditure and the national poverty line, which is ETB $^{5} 315$ per month per person in 2011 prices, we categorize households into poor and non-poor. We use the empirical measure of poverty proposed by (Foster et al. 1984). Poverty at time $t=1, \ldots, T$ in a population of $n$ households with incomes or consumption $y_{1 t}<y_{2 t}<y_{n t}$ is:

$$
\mathrm{p}_{\alpha \mathrm{t}}=\frac{\sum_{\mathrm{i}=1}^{\mathrm{m}_{\mathrm{t}}}\left(\frac{\mathrm{z}-\mathrm{y}_{\mathrm{it}}}{\mathrm{z}}\right)^{\alpha}}{\mathrm{n}}
$$

where $y_{i t} \leq z$ if $i \leq m_{t}$. Note that for $\alpha=0$, the measure is simply the head count index. For $\alpha=1$ it is the poverty gap, averaged over the population and expressed as a proportion of the poverty line. Note that in this paper we focus on the World Bank's definition of poverty, "pronounced deprivation in well-being". Therefore, according to the definition, poor households are those that do not have enough income or consumption to put them above the national poverty line, which is the adequate minimum threshold. The poverty line is the minimum amount of money required to afford the food that meets minimum caloric intake requirements and essential non-food items World Bank (2005). For this study we use the national poverty line of Ethiopia, which is ETB 3781, using 2011 prices.

According to Hoddinott and Quisumbing (2010), Moser (1998) and Alwang et al. (2001), poverty and vulnerability can be distinguished as the latter incorporates uncertainty. Therefore, we use different approaches to measure vulnerability. Vulnerability is defined as the likelihood that at any given time in the future, an individual will have a level of welfare below some norm or benchmark. In the simplest case, given the current condition, vulnerability measures the probability of falling below the poverty line in a given time horizon (Baker 2000). Vulnerability as uninsured exposure to risk (VER), vulnerability as low expected utility (VEU) and vulnerability as expected poverty (VEP) are three conceptual approaches used to measure vulnerability (Hoddinott and Quisumbing 2003). The VEP and VEU approaches are ex-ante analysis and require cross-sectional data. They predict the probability of being poor in the future based on the current level of consumption. The VER requires panel data. In the absence of panel data, one can analyze vulnerability to poverty by using predicted probabilities and the consumption attached to those values. With panel data, we use the actual distribution of consumption of the sample households and analyze the movement of households in and out of poverty by using the poverty transition matrix.

Poverty assessment helps us to measure the effects of past interventions on welfare, and allows us to identify who is poor at a point in time (Haughton and Khandker 2009). However, the well-being of a household depends not only on its current income or consumption, but also its exposure to different types of shocks. Due to uncertain income or consumption, households that are non-poor this year may fall into poverty next year. Similarly, a household that is poor this year may or may not escape poverty next year. As a result, it is very important to categorize households based on their past and current income/consumption

51 US \$ was equivalent to ETB 18.01 (July 2012). 
level and then identify households as vulnerable, chronically poor or non-poor (Haughton and Khandker 2009). In our case, the movement of households in and out of poverty between 2012 and 2016 is assessed using a poverty transition matrix presented in Table 2 . The result of the matrix, which is a cross-classification of the households' poverty status at different points in time, is shown in the results section (see Table 2).

\subsection{Estimating the Impact of Technologies on Poverty and Vulnerability}

Using real per capita consumption expenditure in each round, households are divided into three poverty categories: chronically poor, vulnerable and non-poor. We assumed that the poverty categories can be ordered since we base our classification on the level of real per capita consumption expenditure where the chronically poor situation is the worst to be in and the non-poor category is the best situation. The objective is to analyze the impact of the technology sets mentioned above on the different poverty profiles of households. The ordered probit model is used to analyze the effect of the technology variables on poverty and vulnerability. We specified the model following Long and Freese (2014) and Wooldridge (2002). The ordered response variable has three outcomes taking the value 1 if the household is poor during all the three rounds, 2 if the household is poor at least once and 3 if the household is non-poor for all rounds of the panel. The ordered response variable (y) conditional on the explanatory variables (x) can be derived from the latent variable model. Assume that the latent variable $\mathrm{y}^{*}$ is determined by:

$$
\mathrm{y}^{*}=\mathrm{x} \beta+\mathrm{e}, \quad \mathrm{e} \mid \mathrm{x} \sim \operatorname{Normal}(0,1)
$$

where $\beta$ is a $K \times 1$ and, for reasons $\mathrm{x}$ does not contain a constant. In our case with three categorical variables, we will have two cut points. Given the standard normal distribution for $\mathrm{e}$, the conditional distribution of $\mathrm{y}$ given $\mathrm{x}$ can be computed as:

$$
\begin{aligned}
& \mathrm{p}(\mathrm{y}=1 \mid \mathrm{x})=\mathrm{p}\left(\mathrm{y}^{*} \leq \mathrm{k}_{1} \mid \mathrm{x}\right)=\mathrm{p}\left(\mathrm{x} \beta+\mathrm{e} \leq \mathrm{k}_{1} \mid \mathrm{x}=\Phi\left(\mathrm{k}_{1}-\mathrm{x} \beta\right)\right. \\
& \mathrm{p}\left((\mathrm{y}=2 \mid \mathrm{x})=\mathrm{p}\left(\mathrm{k}_{1} \leq \mathrm{y}^{*} \leq \mathrm{k}_{2} \mid \mathrm{x}\right)=\mathrm{p}\left(\mathrm{x} \beta+\mathrm{e} \leq \mathrm{k}_{1} \mid \mathrm{x}\right)=\Phi\left(\mathrm{k}_{2}-\mathrm{x} \beta\right)-\Phi\left(\mathrm{k}_{1}-\mathrm{x} \beta\right)\right. \\
& \mathrm{p}\left(\mathrm{y}=3 \mid \mathrm{x}=\mathrm{p}\left(\mathrm{y}^{*} \geq \mathrm{k}_{3} \mid \mathrm{x}\right)=\mathrm{p}\left(1-\Phi\left(\mathrm{k}_{13}-\mathrm{x} \beta\right)\right.\right.
\end{aligned}
$$

The sum of the probabilities gives unity. The parameters $\mathrm{k}$ and $\beta$ can be estimated by maximum likelihood. In the present paper, we are interested in how ceteris paribus changes in the elements of technology adoption affect the response probabilities, $P(y=j \mid x), j=1,2, . . j)$. The partial effects of the explanatory variables on the different categories can be computed as:

$$
\begin{aligned}
& \frac{\partial \mathrm{y}_{0}(\mathrm{x})}{\partial \mathrm{x}_{\mathrm{k}}}=-\beta_{\mathrm{k}} \Phi\left(\mathrm{k}_{1}-\mathrm{x} \beta\right), \quad \frac{\partial \mathrm{p}_{\mathrm{J}}(\mathrm{x})}{\partial \mathrm{x}_{\mathrm{k}}}=\beta_{\mathrm{k}} \Phi\left(\mathrm{k}_{\mathrm{J}}-\mathrm{x} \beta\right) \\
& \frac{\partial \mathrm{y}_{\mathrm{j}}(\mathrm{x})}{\partial \mathrm{x}_{\mathrm{k}}}=\beta_{\mathrm{k}} \Phi\left[\left(\mathrm{k}_{\mathrm{j}-1}-\mathrm{x} \beta\right)-\left(\mathrm{k}_{\mathrm{j}}-\mathrm{x} \beta\right)\right], \quad 0<j<J
\end{aligned}
$$

where $y_{i}$ represents three household ordered poverty categories of poverty transition:

$Y_{0}$ households that are under the poverty line in all the three periods will be given a value of 1 (chronically poor); 
$Y_{1}$ households that have changed their status at least once during the three periods will be given a value of 2 (vulnerable) and

$Y_{2}$ households that are always non-poor (whose consumption level is persistently above the poverty line) will be given a value of 3 (always non-poor)

A Brant test for parallel regression/proportional odds assumption is tested. The Brant test statistic is not significant providing the evidence that the parallel regression assumption has not been violated.

\section{Data and Description of Explanatory Variables}

\subsection{Data and Study Area}

Our data come from three waves of farm household survey collected from 390 households that are drawn from the 2012 nationally representative baseline survey conducted by the International Food Policy Research Institute (IFPRI) and Agricultural Transformation Agency (ATA) in Ethiopia. The baseline survey covers the four main regions of Ethiopia, namely Tigray, Amhara, Oromia and Southern Nations Nationalities and Peoples (SNNP). In their sampling procedure, the ATA/IFPRI specifically used a three-stage stratified random sampling procedure (Spielman et al. 2012; Minot and Sawyer 2013). In the first stage, 100 woredas (districts) were randomly selected. In the second stage, two kebelles ${ }^{6}$ were randomly selected from each of the 100 woredas. And thirdly, fifteen farm households were randomly selected from each of the 200 kebelles. $^{7}$ As a result, the total sample size for the baseline survey is 3000 .

Our analysis relies on those sample households drawn from the ATA/IFPRI baseline survey households that are located in Southern Ethiopia covering part of Oromia and SNNPs regions. From those two regions, we considered 15 representative woredas, 2 Kebelles from each of the woredas except Agarfa where we had to drop one of the Kebelles due to security issues during the 2014 survey round. The Woredas (clusters) were selected in such a way that the major climatic and agro-ecological variations of the country were included (Table S1). Nine of the 15 woredas are located in SNNP region and the remaining 6 are located in Oromia region. For our analysis, we used three rounds of panel data with a total sample of 390 households. The first round data come from the 2012 baseline survey and we conducted the second and third rounds in 2014 and 2016 tracking the same panel of the 390 farm households. Our sample households are limited only in the two of the four regions because of budget and logistical constraints. However, our sub-sample farm households are diverse in terms climatic and agro-ecological characteristics and in turn agricultural production. We used a balanced panel data regression analysis; and the attrition rate between 2012 and 2014 is zero whereas the attrition rate between 2014 and 2016 is $2.5 \%$; the systematic attrition rate was tested and there is no significant difference in the regression analysis (with attrition and without attrition). Both the follow up rounds and the

\footnotetext{
${ }^{6}$ One of the Kebelles in Agarfa Woreda (Oromia region) was dropped because of accessibility and security issues we faced during the 2014 survey round.

7 The smallest administrative unit of Ethiopia.
} 
Table 1 Description of the variables in the regression models

\begin{tabular}{|c|c|c|}
\hline Variables & Mean & SD \\
\hline Real per capita consumption expenditure (ETB) & 412 & 416 \\
\hline Poverty status ( $=1$ if chronically poor, $2=$ vulnerable and $3=$ non-poor) & 1.9 & 0.62 \\
\hline Gender (dummy, $=1$ if the household head is male, 0 otherwise) & 0.83 & 0.37 \\
\hline Household size (number of family members) & 6.4 & 2.34 \\
\hline Age (age of the household head in years) & 46.86 & 14.09 \\
\hline Dependency ratio (the ratio of non-working and working household members) & 0.48 & 0.20 \\
\hline Land size (total farm land owned in ha) & 1.5 & 1.5 \\
\hline Off-farm income (dummy, $1=$ if the household earns off-farm income, 0 otherwise) & 0.5 & 0.48 \\
\hline Irrigation (dummy, $1=$ if the household irrigates at least one plot of land, 0 otherwise) & 0.05 & 0.22 \\
\hline The square of age of household head & 2395 & 1482 \\
\hline Livestock (the number of cows, sheep and goats measured in TLU) & 4.16 & 4.69 \\
\hline Drought (dummy, $1=$ if the household experienced any adverse shock, 0 otherwise) & 0.07 & 0.25 \\
\hline Estimated loss due to shock (ETB) & 1345 & 5190 \\
\hline Number of shocks reported per household & 0.29 & 0.62 \\
\hline Value of coping strategies (ETB) & 2728 & 8988 \\
\hline Region $(1=$ SNNPR, $0=$ Oromia $)$ & 0.64 & 0.48 \\
\hline $\mathrm{F}_{1} \mathrm{~V}_{0} \mathrm{~T}_{0} \mathrm{C}_{0} \mathrm{P}_{0}$ (dummy, $1=$ only chemical fertilizer) & 0.11 & 0.3 \\
\hline $\mathrm{F}_{0} \mathrm{~V}_{1} \mathrm{~T}_{0} \mathrm{C}_{0} \mathrm{P}_{0}$ (dummy, $1=$ only improved seed) & 0.03 & 0.17 \\
\hline $\mathrm{F}_{1} \mathrm{~V}_{0} \mathrm{~T}_{1} \mathrm{C}_{0} \mathrm{P}_{0}$ (dummy, $1=$ chemical fertilizer and improved seed $)$ & 0.02 & 0.17 \\
\hline $\mathrm{F}_{1} \mathrm{~V}_{0} \mathrm{~T}_{0} \mathrm{C}_{1} \mathrm{P}_{0}$ (dummy, $1=$ chemical fertilizer and contour plough) & 0.06 & 0.24 \\
\hline $\mathrm{F}_{1} \mathrm{~V}_{0} \mathrm{~T}_{0} \mathrm{C}_{0} \mathrm{P}_{1}$ (dummy, $1=$ chemical fertilizer and pesticide) & 0.06 & 0.25 \\
\hline $\mathrm{F}_{1} \mathrm{~V}_{1} \mathrm{~T}_{1} \mathrm{C}_{0} \mathrm{P}_{0}$ (dummy, $1=$ chemical fertilizer, improved seed, terraces) & 0.03 & 0.16 \\
\hline $\mathrm{F}_{1} \mathrm{~V}_{1} \mathrm{~T}_{0} \mathrm{C}_{1} \mathrm{P}_{0}$ (dummy, chemical fertilizer, improved seed, contour plough) & 0.5 & 0.2 \\
\hline $\mathrm{F}_{1} \mathrm{~V}_{1} \mathrm{~T}_{0} \mathrm{C}_{0} \mathrm{P}_{1}$ (dummy, chemical fertilizer, improved seed pesticide) & 0.04 & 0.2 \\
\hline $\mathrm{F}_{1} \mathrm{~V}_{0} \mathrm{~T}_{1} \mathrm{C}_{1} \mathrm{P}_{0}$ (dummy, chemical fertilizer, terraces, contour plough) & 0.02 & 0.15 \\
\hline $\mathrm{F}_{1} \mathrm{~V}_{0} \mathrm{~T}_{0} \mathrm{C}_{1} \mathrm{P}_{1}$ (dummy, chemical fertilizer, contour plough and pesticide) & 0.15 & 0.3 \\
\hline $\mathrm{F}_{1} \mathrm{~V}_{1} \mathrm{~T}_{1} \mathrm{C}_{1} \mathrm{P}_{0}$ (Dummy, chemical fertilizer, improved seed, terraces, contour plough) & 0.03 & 0.17 \\
\hline $\mathrm{F}_{1} \mathrm{~V}_{0} \mathrm{~T}_{1} \mathrm{C}_{1} \mathrm{P}_{1}$ (Dummy, chemical fertilizer, terraces, contour plough and pesticide) & 0.03 & 0.17 \\
\hline $\mathrm{F}_{1} \mathrm{~V}_{1} \mathrm{P}_{1} \mathrm{~T}_{1} \mathrm{C}_{1}$ (all the five technologies) & 0.02 & 0.15 \\
\hline $\mathrm{F}_{1} \mathrm{~V}_{1} \mathrm{~T}_{0} \mathrm{C}_{1} \mathrm{P}_{1}$ (four technologies except terracing) & 0.04 & 0.2 \\
\hline
\end{tabular}

Source: Pooled data-Ethiopia ATA Baseline (2012) Survey and DFG-Ethiopia-technology adoption survey (2014 and 2016). Attrition rate between 2014 and 2016 was 10/400 $=2.5 \%$

F, V, T, C and P refer to chemical fertilizer, improved seed variety, terraces, contour plough and pesticide

Subscript ' 0 ' denotes non-adoption while ' 1 ' denotes adoption

baseline survey questionnaire have rich information on demography, asset ownership, technology and input use, consumption, production, and health.

\subsection{Description of Explanatory Variables}

In this sub-section we explain our prior expectations regarding the relationships between the explanatory variables included in the model and consumption, poverty and vulnerability of rural households. 
Table 2 Poverty transition matrix

\begin{tabular}{llllll}
\hline \multirow{2}{*}{ Year } & 2014 & & & 2016 & \\
\cline { 5 - 6 } \cline { 5 - 5 } & Poor & Non-poor & & Poor & Non-poor \\
\hline 2012 & & & & \\
Poor & $\mathbf{4 6}$ & 29 & $\mathbf{2 8}$ & 47 \\
Non-poor & 6 & $\mathbf{1 9}$ & 3 & $\mathbf{2 2}$ \\
2014 & & & & \\
Poor & & & $\mathbf{2 3}$ & 29 \\
Non-poor & & & 8 & $\mathbf{4 0}$ \\
\hline
\end{tabular}

Source: Own computation

Technology Choice Sets The five technologies and practices included in this study (chemical fertilizer, pesticides, improved seeds, terracing, and contour ploughing) and their combinations measured as dummy variables taking the value of 1 if the household adopted the technologies in any of their plots and 0 otherwise (see Table 1, are all expected to increase agricultural output and productivity. This increase in production should lead to increase in consumption as well as reduction in poverty and vulnerability. However, in the case of severe shocks leading to a complete crop failure, the adoption of chemical fertilizer, for instance, may cause households to suffer large financial losses, because of input costs spent. To improve the resilience of crops to climatic shocks, and at the same time improve soil fertility, different SWC techniques may prove useful. For example, mulching, composting and contour ploughing are assumed to increase soil organic matter and water holding capacity, leading to improved crop productivity. This, in turn, should lead to higher food availability and income available for consumption, leading to reduced poverty. Despite the high investment costs of SWC practices like terracing, it is supposed that the long-term effects will lead to increased consumption and reduced poverty and vulnerability.

Number of Livestock and Farm Size Possession of livestock and farm size as indicator variables for wealth are used to capture the impact of household wealth on adoption and welfare. The number of livestock representing the mean level of asset ownership of households measured in Tropical Livestock Unit (TLU) is also expected to influence consumption, poverty and vulnerability. In Ethiopia, livestock is an important source of capital during times of food shortage. It serves both as a source of liquid assets as well as a productive resource in the form of draft power. Therefore, building or having larger stocks of animals is considered to positively influence household consumption and thus reduce poverty and vulnerability. Land size measured in hectares is expected to influence consumption positively and help farmers to escape poverty or remain non-poor.

Demographic Characteristics Family size, the number of working household members, the dependency ratio and the educational status of the household head also influence poverty and vulnerability. Education represented by the number of years of formal schooling of the household head is hypothesized to have a positive effect on technology adoption and thus expected to influence consumption positively and reduce poverty and vulnerability. The age of the household head may have both positive and negative effects as it captures farming experience, attitudes towards new technologies and labor capacity. Gender represented by a dummy variable taking the value 1 if the household head is male and 0 for female headed households, expected to influence consumption. Male headed households are expected to have a higher level of consumption and lower poverty and vulnerability. 
Experience of Shocks Smallholders in Ethiopia are prone to various types of shocks such as drought, flooding, pests and diseases which may be responsible for the perpetuation of poverty. Thus, household's experience of adverse shocks, the number of shocks reported $^{8}$ and the resulting amount of loss in monetary values are hypothesized to increase vulnerability to poverty. The amount of money spent on coping strategies may have both negative and positive effects. Since households may sell their assets or take credit to smooth consumption (Sharma et al. 2000), this may reduce poverty and vulnerability in the short run. However, the expense of the coping strategies decrease household's standard of living in the long run as they must repay loans or replace durable assets that were lost due to distress sale. Unlike the other explanatory variables mentioned above, only the last two rounds (2014 and 2016) have detailed information on self-reported shock experience by the sample households. Even though the households were asked to report their shock experience for the past three years in each survey round, it appears that almost all of them reported not have experienced any type of adverse shock in 2012.Therefore, we run a separate regression using the last two rounds controlling for households experience towards adverse shocks.

Off-Farm Income Measured as a dummy variable taking a value of 1 if the household has at least one source of income other than farming is expected to influence consumption. Having other source of income may reduce financial constraints, particularly for poor farmers, enabling them to afford purchase the technologies. However, the net effect of off-farm income is a priori ambiguous, since participation in off-farm activities may restrict production in agriculture (Wozniak 1984).

Region The sample households are located in two regions (SNNP and Oromia), and we expect to see differences in the level of consumption as well as poverty and vulnerability in the two regions.

Table 1 presents the definitions and descriptive statistics of the variables included in the regression analysis using the pooled data of the three rounds. The mean of the continuous dependent variable (real per capita consumption expenditure) for the pooled data is ETB 412. The mean age of the household head is 47 and on average sample households have dependency ratio of 0.48 . The technology choice sets as the main objective of this paper are expressed as dummy variables (see Table 1). On average, the combinations of the different technologies such as chemical fertilizer, improved seed and contour ploughing (50\%); only chemical fertilizer (15\%); chemical fertilizer, contour plough and pesticide (11\%) are the most common technology choice sets observed in the sample farmers. The mean level of asset holdings as a measure of welfare which as well influences the level of household consumption, represented by the mean number of livestock owned (TLU) and land size in ha are 4 and 1.5, respectively. On average 50\% of the sample households earn off-farm income. With regard to investment in irrigation, only 5\% of the households use irrigation. Regarding the self-reported shock experience of sample households, only $7 \%$ of them reported to have experienced an adverse shock at least once between 2011 and 2016. The mean value of estimated loss due to shock is ETB 1345 and the mean expenditure on coping strategies against the adverse shocks reported is ETB 2728. SNNPR covers $64 \%$ of the sample households and the remaining $36 \%$ of the sample households are from Oromia region.

\footnotetext{
${ }^{8}$ The different types of shocks reported were flooding, drought, illness of a family member as well as open grazing.
} 


\section{Results and Discussion}

\subsection{Poverty and Vulnerability Profile of Households}

The primary focus of the study is to analyze the effect of PETs and SWC measures and their combinations on consumption, poverty and vulnerability. Real per capita consumption expenditure for food and other essential non-food items, such as clothing and footwear, is used as a proxy variable to measure poverty. Using the national poverty line in 2011 prices, sample households are grouped into poor and non-poor households, where the poor are those households whose consumption level is below the national poverty line and the non-poor are those households whose consumption level is above the national poverty line. The movement of sample households in and out of poverty between 2012 and 2016 is analyzed using a poverty transaction matrix presented in Table 2. Bold figures indicate the share of households that stayed in the same poverty category between two survey rounds. A visual inspection of the matrix show that household's poverty status is not stable over time. For instance, of the 290 poor households in 2012 , only $46 \%$ and $28 \%$ remained poor in 2014 and 2016, respectively. Similarly, of the 100 non-poor households in 2012, 19\% and 22\% remained non-poor in 2014 and 2016, respectively.

Looking at the overall incidence of poverty in all of the three rounds of the data, we computed the headcount ratio that is the share of households living below the national poverty line, and the result shows that poverty has declined throughout the survey rounds. The 2012 headcount ratio was 70\%; it fell to 50\% and 30\% in 2014 and 2016, respectively. This finding is consistent with other documentation on Ethiopia's progress in alleviating poverty and food insecurity (see World Bank 2015). The World Bank report reveals that the rural poverty headcount ratio declined from $45.4 \%$ in 2000 to $30.4 \%$ in 2011 . However, one can see that higher proportion of households entered poverty between 2014 and 2016 (8\%) compared with 2012 and 2014 (6\%). This suggests that the incidence of vulnerability to poverty is more prevalent than poverty itself, which was showed by other researchers like Haughton and Khandker (2009).

\subsection{Differences in Household Characteristics by Poverty Status}

The poverty grouping helps us to examine the differences between the poor and non-poor households in several demographic, economic, and institutional variables. These differences are provided in Table 3 (also see Table 8 in the appendix part).

Table 3 indicates that female headed households tend to be poorer than male headed households throughout the survey rounds, though the proportion of poor households in both gender groups declined significantly. The descriptive results also show that non-poor households tend to have larger families throughout the survey rounds. Similarly, non-poor households have more household members who are economically active. This result suggests that non-poor households are better endowed with an economically active labor force. In both cases the mean difference between the two categories is significantly different at the $1 \%$ level of significance. However, the dependency ratio between poor and non-poor households is not significantly different for all three panel rounds. Regarding the education of the household head, the results show that in all rounds non-poor households have better educated heads than poor households at the $1 \%$ level of statistical significance, though the 


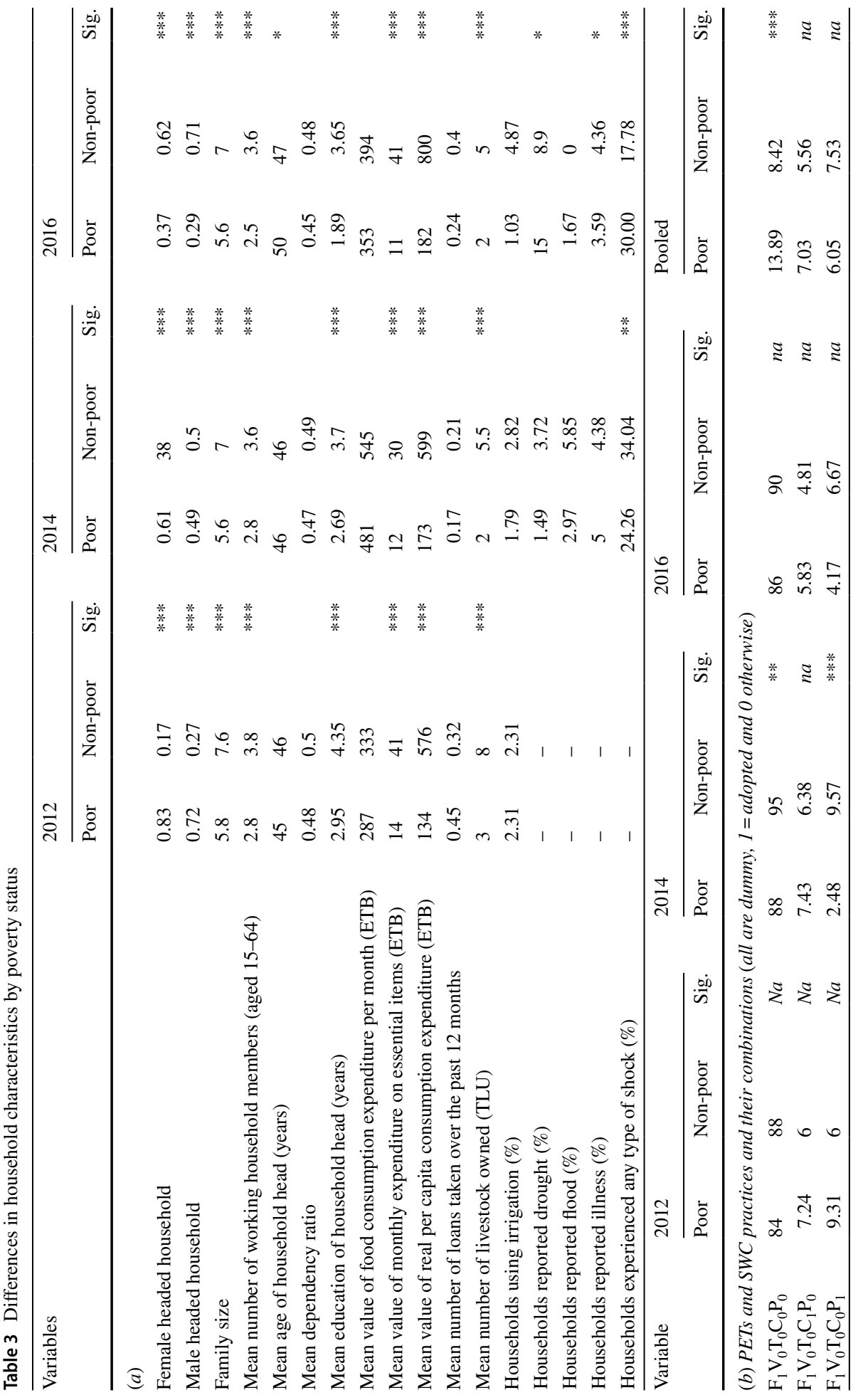




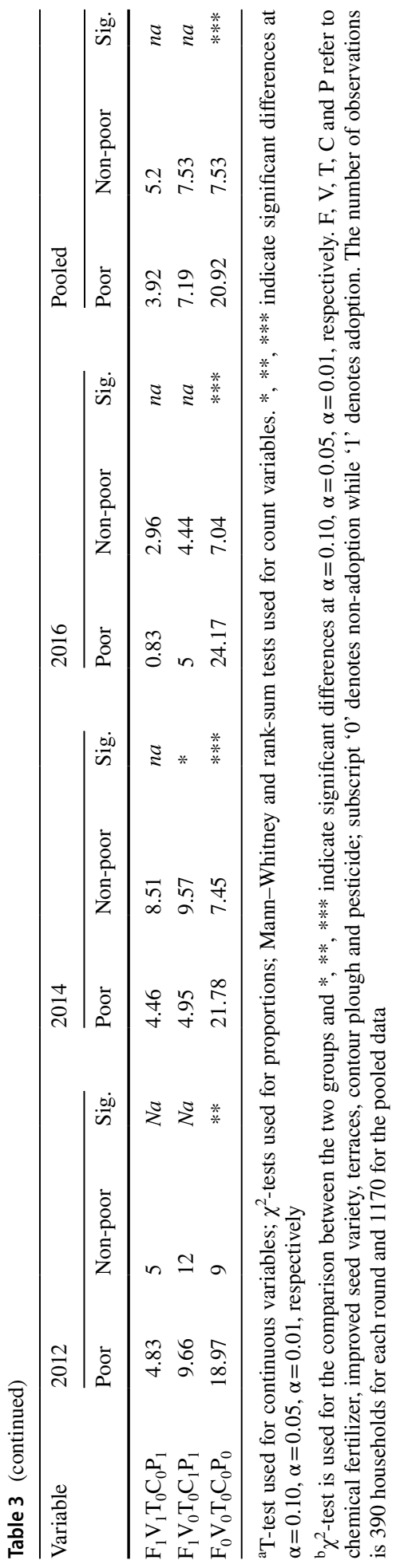


two groups of households are not statistically significantly different in terms of the age of their household head in 2012 and 2014.

With regard to consumption expenditure, there is no statistical difference in real per capita food consumption expenditure in all survey rounds. However, non-poor households have a statistically higher level of per capita consumption for other non-food items. Nonpoor households also have higher per capita consumption for both food and non-food items in all three rounds at the $1 \%$ level of significance. Asset ownership in rural Ethiopia, such as ownership of livestock, is an integral part of smallholder farmers' production systems. Livestock provides manure and draft power for farm operations and serves as precautionary savings given imperfect financial markets. We find that non-poor households keep a significantly higher number of livestock than poor households. Concerning the differences in adoption of agricultural technologies, in the 2014 and 2016 survey rounds a significantly higher proportion of non-poor households used chemical fertilizer with no other complementary input. Similarly, there is a significant difference in the adoption of an improved variety; a higher proportion of non-poor households used an improved variety in 2012. However, the results show no significant difference in the use of chemical fertilizer in 2012 and an improved variety in 2014 and 2016. Likewise, a higher proportion of non-poor households use contour ploughing. On the other hand, there is no evidence whether there is a statistical difference between the poor and non-poor in the use of terracing.

With regard to combinations of the technologies considered in the study, the descriptive results show poor households tend to adopt single technologies more frequently than the non-poor. For instance, a significantly higher proportion of poor households tend to adopt only chemical fertilizer and contour ploughing. Similarly, statistically significantly higher proportions of poor households are non-adopters $(21 \%)$ compared with the nonpoor $(7.5 \%)$. On the other hand, there is a significant difference in the adoption of multiple technologies where a higher proportion of non-poor households tend to adopt multiple technologies compared with the poor households.

With regard to information on experience to various shocks, households were asked to report if they had been affected by the different types of shocks in the past 5 years. Data on shock experience, however, was only collected in the 2014 and 2016 rounds. Therefore, we run a separate regression including the shock experience indicator variables as additional regressors using the two rounds of panel data (2014 and 2016). Our descriptive result shows that a higher proportion of poor households reported to be affected by the drought in 2016 compared with non-poor households. However, there was no difference in their experience of drought in 2014. On the contrary, in 2016, a significantly higher proportion of non-poor households experienced illness of a household member. With regard to households' experience of any type of shock between 2009 and 2016, we obtain mixed results for the two groups. In 2014, a higher proportion of non-poor households reported being affected by any shock than poor households (significant at 5\%). The reverse holds true in 2016 when a higher proportion of poor households reported being affected by shocks relative to non-poor households (significant at $1 \%$ ).

In summary, poor households own less livestock, have fewer economically active household members, a smaller family size with a female and less-educated household head. Compared with non-poor households, they also experience more adverse shocks and a lower rate of technology adoption.

The marginal and conditional probabilities of improved PETS and SWC measures are also presented in Table 4, which indicates complementarity among technologies; adoption of one technology improves the likelihood of adoption of the other technology. The adoption of improved seed variety, for instance, increases the adoption of chemical fertilizer 


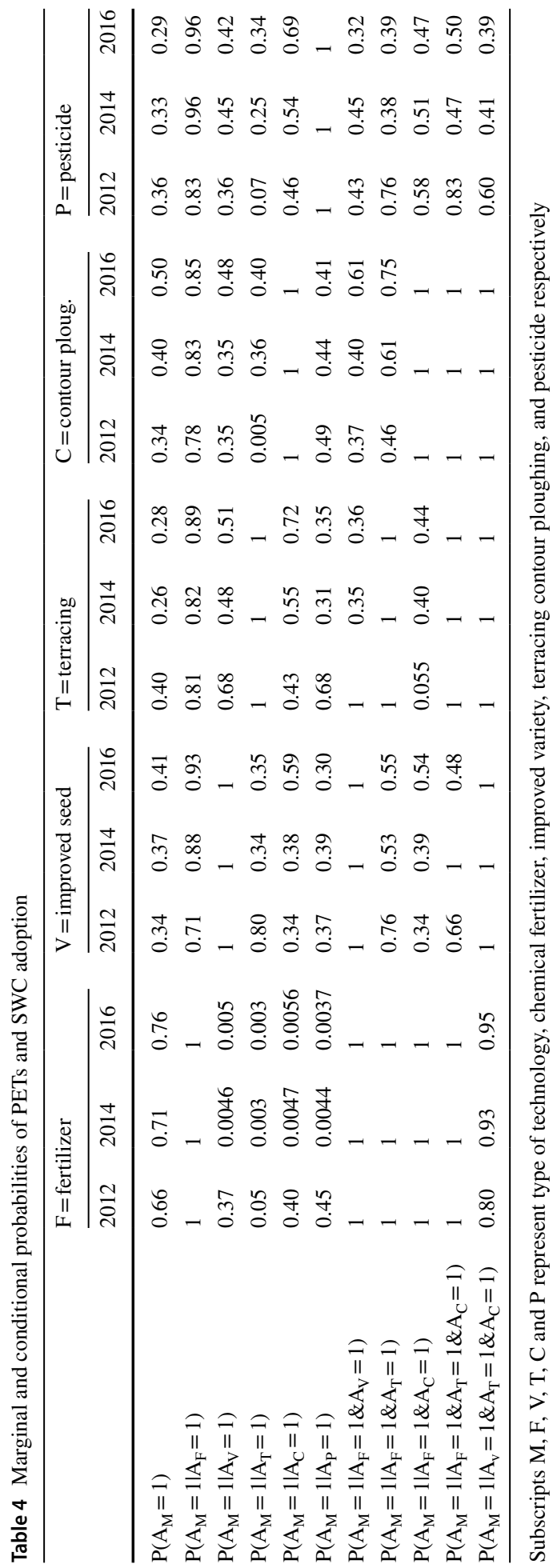


Table 5 The expected actual and counterfactual consumption estimates and the average treatment effect (ATT) on adopters

\begin{tabular}{lllll}
\hline Set of technologies & $\begin{array}{l}\text { Actual observed } \\
\text { consumption }\end{array}$ & $\begin{array}{l}\text { Counterfactual (consumption if a } \\
\text { household did not adopt) }\end{array}$ & ATT & Sig \\
\hline $\mathrm{F}_{1} \mathrm{~V}_{0} \mathrm{~T}_{0} \mathrm{C}_{0} \mathrm{P}_{0}$ & 5.1 & 4.44 & 0.66 & $* *$ \\
$\mathrm{~F}_{1} \mathrm{~V}_{0} \mathrm{~T}_{0} \mathrm{C}_{1} \mathrm{P}_{1}$ & 5.72 & 5.65 & 0.07 & $*$ \\
$\mathrm{~F}_{1} \mathrm{~V}_{0} \mathrm{~T}_{0} \mathrm{C}_{0} \mathrm{P}_{1}$ & 5.7 & 4.96 & 0.74 & $* *$ \\
$\mathrm{~F}_{1} \mathrm{~V}_{1} \mathrm{~T}_{0} \mathrm{C}_{0} \mathrm{P}_{1}$ & 5.8 & 5 & 0.8 & $* *$ \\
$\mathrm{~F}_{1} \mathrm{~V}_{1} \mathrm{~T}_{1}, \mathrm{~F}_{1} \mathrm{~T}_{1} \mathrm{C}_{1}, \mathrm{~F}_{1}$ & 6.05 & 0.01 & $* *$ \\
$\mathrm{~F}_{1} \mathrm{~V}_{1} \mathrm{~T}_{1} \mathrm{C}_{1} \mathrm{P}_{1}, \mathrm{~F}_{1} \mathrm{~V}_{1} \mathrm{C}_{1}, \mathrm{~F}_{1} \mathrm{~V}_{1} \mathrm{~T}_{1} \mathrm{C}_{1}$, & 6.06 & & & \\
$\mathrm{~F}_{1} \mathrm{~T}_{1} \mathrm{C}_{1} \mathrm{P}_{1}^{\mathrm{bl}}$ & & & 0.8 & $*$ \\
$\mathrm{~V}_{1}, \mathrm{~F}_{1} \mathrm{~T}_{1}$ and $\mathrm{F}_{1} \mathrm{C}_{1}^{2}$ & 5.5 & 4.7 & & \\
\hline
\end{tabular}

${ }^{\mathrm{a}} \mathrm{F}, \mathrm{V}, \mathrm{T}, \mathrm{C}$ and $\mathrm{P}$ denotes chemical, improved seed, terraces, contour plough and pesticide, respectively

${ }^{b} \mathrm{~F}_{1} \mathrm{~V}_{1} \mathrm{~T}_{1}, \mathrm{~F}_{1} \mathrm{~T}_{1} \mathrm{C}_{1}, \mathrm{~F}_{1} \mathrm{~V}_{1} \mathrm{~T}_{1} \mathrm{C}_{1} \mathrm{P}_{1}, \mathrm{~F}_{1} \mathrm{~V}_{1} \mathrm{C}_{1}, \mathrm{~F}_{1} \mathrm{~V}_{1} \mathrm{~T}_{1} \mathrm{C}_{1}$, and $\mathrm{F}_{1} \mathrm{~T}_{1} \mathrm{C}_{1} \mathrm{P}_{1}$ were merged because of insufficient observations for separate regressions

${ }^{1}$ Included are $\mathrm{F}_{1} \mathrm{~V}_{1} \mathrm{~T}_{1}, \mathrm{~F}_{1} \mathrm{~T}_{1} \mathrm{C}_{1}, \mathrm{~F}_{1} \mathrm{~V}_{1} \mathrm{~T}_{1} \mathrm{C}_{1} \mathrm{P}_{1}, \mathrm{~F}_{1} \mathrm{~V}_{1} \mathrm{C}_{1}, \mathrm{~F}_{1} \mathrm{~V}_{1} \mathrm{~T}_{1} \mathrm{C}_{1}$, and $\mathrm{F}_{1} \mathrm{~T}_{1} \mathrm{C}_{1} \mathrm{P}_{1}$. The subscript ' 0 ' for nonadoption is missing to save space for the remaining technologies

${ }^{2}$ Included are $\mathrm{V}_{1}, \mathrm{~F}_{1} \mathrm{~T}_{1}$, and $\mathrm{F}_{1} \mathrm{C}_{1}$. We combine these practices because there are no adequate observations to run separate regressions for each practice. The subscript ' 0 ' for non-adoption is missing to save space for the remaining technologies

and vice versa. Sometimes adoption of one technology may also decrease the likelihood of adoption of the other technology in cases of substitutability. The use of organic fertilizer for example may substitute the use of chemical fertilizer. As shown in the table below (Table 4), the probability of adopting chemical fertilizer when conditional on whether the household also adopted improved seed on average is greater than $85 \%$. Likewise, adoption of chemical fertilizer increases the likelihood of adoption of the other four technologies. The most popular technology adopted in our sample households is chemical fertilizer followed by improved seed.

\subsection{Econometric Results}

Using per capita consumption expenditure as a dependent variable, we estimated a twostage endogenous switching regression multinomial logit (ESMNL) regression model to analyze the impact of technologies on consumption. Following the Mundlak approach, we also run a random effects model and the results are qualitatively similar to those of the ESMNL regression model. Our results support the presence of both time varying and timeinvariant unobserved heterogeneity that affect both technology set choices and outcome variables (consumption expenditure and poverty profile), emphasizing the importance of controlling selection bias in evaluating technology sets. The outcome regression equation results are presented in Tables 5 and 6.

Table 5 shows the expected actual, counter factual and average treatment effect (ATT) on adopters. The ATT is the difference between the expected actual value of consumption and the counterfactual outcome. The ATT results show that all the technology sets, except the category for minor combinations, have positive and significant impacts on consumption expenditure. The difference to the log values can be converted to percentages and the results indicate that adopting only chemical fertilizer with no other 
Table 6 Random effects coefficients using the Mundlak approach and panel data

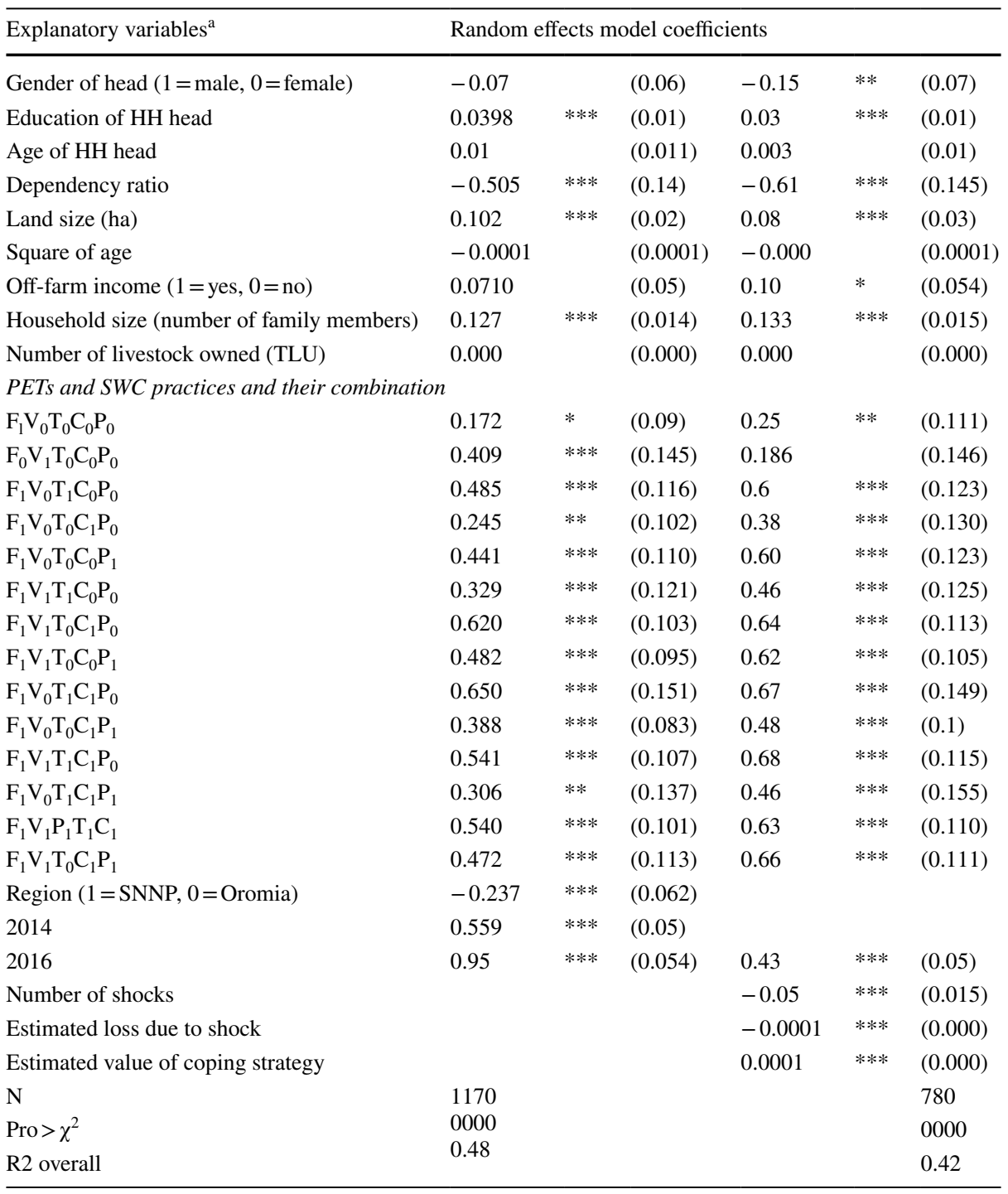

*Robust standard errors are given in Parentheses. *, **, *** indicate significant differences at $\alpha=0.10$, $\alpha=0.05, \alpha=0.01$, respectively. The dependent variable is the natural log of real consumption expenditure

${ }^{\text {a }}$ The coefficient for irrigation that was included in the model is not significantly different from zero. The coefficients for the mean of the time varying predictor variables and the mean of the inverse Mills ratio were also not significantly different from zero

complementary input significantly increases consumption by $15 \%$. On the other hand, combining chemical fertilizer with contour ploughing significantly increases consumption by $1 \%$. The unexpected result, that complementing chemical fertilizer with contour ploughing has lesser consumption effects, could be because our measure of adoption does not consider the intensity of adoption. Similarly, the joint adoption of chemical fertilizer and pesticide increases consumption by $15 \%$. The adoption of the three 
technologies (chemical fertilizer, improved seed and pesticide) significantly increases consumption expenditure by $16 \%$. In summary, the results show that the adoption of multiple technologies increases consumption. In our case, the highest impact is observed when at least three of the technologies considered here are adopted together. Recent empirical evidence by Kassie et al. (2015, 2018), Manda et al. (2016), and Teklewold et al. (2013) in Ethiopia and elsewhere also demonstrate that a combination of technologies provide higher net returns than when only a single technology is adopted.

The random effects model estimation using the Mundlak approach is presented in Table 6. The random effects estimates support the outcomes observed in Table 5, which are obtained by using separate regressions for each practice and the results are qualitatively similar. The adoption of technologies considered in this study (chemical fertilizer, improved seed, terracing and contour plough) and their combinations have the anticipated effect and are found to be positively associated with consumption. The adoption of chemical fertilizer and improved seed each with no other complementary input increases consumption by $17 \%$ and $40 \%$, respectively. Overall, most of the technology sets included in the model appear to have a positive and statistically significant impact on consumption, as expected. The model result also reveals that the highest impact of adoption is observed for the technology combination chemical fertilizer and improved seed combined with at least one of the SWC practices, which increases consumption by more than $60 \%$.

Regarding household demographics, the gender of the household head is negatively associated with consumption. It is shown that male headed households have $15 \%$ less consumption than female headed households. However, the poverty classification shows that female headed households are poorer with fewer assets. In this analysis, the food consumption calculation is based on the seven-day recall approach and women headed households may spend more on food than investment goods contrary to male headed households. Household size represented by the number of family members is positively associated with consumption over time. An additional household member significantly increases real consumption per capita by more than $12 \%$. This positive effect is similar to the findings of Demeke et al. (2011) in Ethiopia, suggesting household size when controlling for dependency ratio influences food security positively. The age of the household head and the number of livestock are not significant factors of consumption in this model. Farm size has a positive and significant effect on both models. Though weakly significant, income other than farming has a positive impact on consumption in the second model. To control for spatial effects, the region dummy was included in the model. As expected, the estimates show that households located in SNNPR have about 23\% less consumption than those in Oromia region. Time dummies were also significant and show an increase in consumption over time. The random effects model results also suggest that money spent on coping strategies is positively associated with consumption.

To analyze the impact of adoption of single technologies and their possible combinations on the different poverty categories, an ordered probit model is employed using the 2012 baseline data. The model's marginal effects estimates are presented in Table 7. The results show that the adoption of single technologies or their combinations have the expected signs and support the previous counterfactual and random effects model analysis. Most of the technology set variables included in the model are significant and have the expected signs. The adoptions of the single technologies or their combinations reduces the likelihood of households being in the chronically poor situation or enable them to move to a better welfare situation, in this case the vulnerable and non-poor categories.

Regarding the demographic characteristics, household size and education of the household head influences the likelihood of households being in the different poverty categories. 
Table 7 Ordered probit model marginal effects

\begin{tabular}{|c|c|c|c|c|c|c|c|c|c|}
\hline \multirow{3}{*}{$\begin{array}{l}\text { Explanatory variables } \\
\text { Gender }\end{array}$} & \multicolumn{9}{|c|}{ Ordered probit model (marginal effects) } \\
\hline & \multicolumn{3}{|c|}{ Chronically poor } & \multicolumn{3}{|c|}{ Vulnerable } & \multicolumn{3}{|l|}{ Non-poor } \\
\hline & 0.05 & & $(0.04)$ & -0.005 & & $(0.009)$ & 0.01 & & $(0.004)$ \\
\hline \multicolumn{10}{|l|}{ (a) } \\
\hline Education of $\mathrm{HH}$ head & -0.14 & $* * *$ & $(0.005)$ & 0.002 & $*$ & $(0.002)$ & 0.01 & $* * *$ & $(0.04)$ \\
\hline Household size & -0.048 & $* * *$ & $(0.008)$ & 0.01 & $* *$ & $(0.004)$ & 0.04 & $* * *$ & $(0.006)$ \\
\hline Age of household head & -0.001 & & $(0.006)$ & 0.0002 & & $(0.001)$ & 0.0009 & & $(0.005)$ \\
\hline Farm size (ha) & 0.005 & & $(0.15)$ & -0.001 & & $(0.003)$ & -0.004 & & $(0.12)$ \\
\hline Other Income & -0.09 & $* * *$ & $(0.03)$ & 0.017 & $*$ & $(0.009)$ & 0.07 & $* * *$ & $(0.024)$ \\
\hline Number of livestock (TLU) & -0.017 & $* * *$ & $(0.008)$ & 0.01 & $*$ & $(0.002)$ & 0.014 & $* * *$ & $(0.004)$ \\
\hline $\begin{array}{l}\text { Region }(\mathrm{SNNPR}=1, \\
\quad \text { Oromia }=0)\end{array}$ & 0.1 & $* *$ & $(0.039)$ & -0.02 & $*$ & $(0.011)$ & -0.08 & $* *$ & $(0.031)$ \\
\hline Age square & 0.000 & & $(0.000)$ & -0.000 & & $(.0001)$ & -0.0001 & & $(0.000)$ \\
\hline $\mathrm{F}_{1} \mathrm{~V}_{0} \mathrm{~T}_{0} \mathrm{C}_{0} \mathrm{P}_{0}$ & 0.120 & $* * *$ & 0.03 & 0.77 & $* * *$ & $(0.03)$ & 0.10 & $* *$ & $(0.031)$ \\
\hline $\mathrm{F}_{0} \mathrm{~V}_{1} \mathrm{~T}_{0} \mathrm{C}_{0} \mathrm{P}_{0}$ & 0.048 & $*$ & 0.025 & 0.71 & $* * *$ & $(0.077)$ & 0.24 & $* *$ & $(0.09)$ \\
\hline $\mathrm{F}_{1} \mathrm{~V}_{0} \mathrm{~T}_{1} \mathrm{C}_{0} \mathrm{P}_{0}$ & 0.202 & & 0.36 & 0.74 & $* * *$ & $(0.23)$ & 0.06 & & $(0.13)$ \\
\hline $\mathrm{F}_{1} \mathrm{~V}_{0} \mathrm{~T}_{0} \mathrm{C}_{1} \mathrm{P}_{0}$ & 0.19 & $* * *$ & 0.068 & 0.74 & $* * *$ & $0.048)$ & 0.064 & $* *$ & $(0.027)$ \\
\hline $\mathrm{F}_{1} \mathrm{~V}_{0} \mathrm{~T}_{0} \mathrm{C}_{0} \mathrm{P}_{1}$ & 0.14 & $* * *$ & 0.04 & 0.76 & $* * *$ & $(0.03)$ & 0.092 & $* * *$ & $(0.034)$ \\
\hline \multirow[t]{2}{*}{ Explanatory variables } & \multicolumn{9}{|c|}{ Ordered probit model (marginal effects) } \\
\hline & chronica & ly poor & & Vulner & able & & Non-poor & & \\
\hline \multicolumn{10}{|l|}{ (b) } \\
\hline $\mathrm{F}_{1} \mathrm{~V}_{1} \mathrm{~T}_{1} \mathrm{C}_{0} \mathrm{P}_{0}$ & 0.13 & & $(0.17)$ & 0.76 & $* * *$ & $(0.047)$ & 0.09 & & 0.14 \\
\hline $\mathrm{F}_{1} \mathrm{~V}_{1} \mathrm{~T}_{0} \mathrm{C}_{1} \mathrm{P}_{0}$ & 0.04 & $*$ & $(0.02)$ & 0.6 & $* * *$ & $(0.092)$ & 0.28 & $* *$ & 0.11 \\
\hline $\mathrm{F}_{1} \mathrm{~V}_{1} \mathrm{~T}_{0} \mathrm{C}_{0} \mathrm{P}_{1}$ & 093 & $* *$ & $(0.04)$ & 0.76 & $* * *$ & $(0.03)$ & 0.14 & $* *$ & 0.06 \\
\hline $\mathrm{F}_{1} \mathrm{~V}_{0} \mathrm{~T}_{0} \mathrm{C}_{1} \mathrm{P}_{1}$ & 0.10 & $* * *$ & $(0.026)$ & 0.76 & $* * *$ & $(0.027)$ & 0.13 & $* * *$ & 0.31 \\
\hline $\mathrm{F}_{1} \mathrm{~V}_{1} \mathrm{~T}_{1} \mathrm{C}_{1} \mathrm{P}_{0}$ & 0.035 & & $(0.07)$ & 0.64 & & $(0.41)$ & 0.12 & & 0.19 \\
\hline $\mathrm{F}_{1} \mathrm{~V}_{0} \mathrm{~T}_{1} \mathrm{C}_{1} \mathrm{P}_{1}$ & 0.107 & & $(0.17)$ & 0.76 & $* * *$ & $(0.034)$ & 0.05 & & 0.067 \\
\hline $\mathrm{F}_{1} \mathrm{~V}_{1} \mathrm{P}_{1} \mathrm{~T}_{1} \mathrm{C}_{1}$ & 0.21 & & $(0.20)$ & 0.72 & $* * *$ & $0.13)$ & 0.192 & & 0.087 \\
\hline $\mathrm{F}_{1} \mathrm{~V}_{1} \mathrm{~T}_{0} \mathrm{C}_{1} \mathrm{P}_{1}$ & 0.06 & $*$ & $(0.03)$ & 0.74 & $* * *$ & $(0.57)$ & 0.089 & $* *$ & 0.034 \\
\hline Prob $>$ chi 2 & 0.0000 & & & & & & & & \\
\hline LR chi2 (26) & 166 & & & & & & & & \\
\hline Psuedo R-square & 0.22 & & & & & & & & \\
\hline $\mathrm{N}$ & 390 & & & & & & & & \\
\hline
\end{tabular}

*Robust standard errors are given in Parentheses. *, **, *** indicate significant differences at $\alpha=0.10$, $\alpha=0.05, \alpha=0.01$, respectively. DP variable for the OL model is poverty status ( $1=$ Chronically poor, $2=$ vulnerable and $3=$ non-poor)

The variable household size has the anticipated sign. Households with more family members are likely to escape the chronically poor category. An additional family member in the household decreases the likelihood of the household being chronically poor by $4.8 \%$. The gender and age of the household head appear not to be significant factors in this model. In line with the hypothesis, the number of livestock and other sources of income significantly improve the poverty status of households. The regional dummy variable estimate shows that households located SNNPR are less likely to escape poverty than those in Oromia. 
Over all, both the random effects and OP model results indicate that there is a strong link between agricultural technology and consumption, poverty, and vulnerability.

\section{Conclusion and Recommendations}

The main objective of this paper is to estimate the impact of agricultural technologies, particularly PETs (chemical fertilizer, pesticide and improved seed) and SWC practices (terraces and contour ploughing) and their possible combinations, on consumption, poverty and vulnerability. The analysis is based on three rounds of balanced household panel data collected in 2012, 2014, and 2016, with a sample size of 390 households. We estimated an endogenous switching multinomial logit model combined with panel data following the Mundlak approach and, assuming a different slope coefficient, we ran seven separate regressions for the different technology combinations. From this regression the expected counterfactual outcomes for the adopters were calculated. Alternatively, following the same approach, we estimated the random effects model while controlling for unobserved heterogeneity. The impact of the technologies on the three poverty categories (chronically poor, vulnerable and non-poor) was also analyzed using the ordered probit model.

The descriptive results reveal that poor households own less livestock and have fewer economically active household members, a smaller family size and a less-educated household head. They also experienced more adverse shocks, spent less on chemical fertilizer, and used improved varieties and pesticides less frequently. The econometric modeling results suggest that PETs and SWC measures and their combinations contribute to the reduction of poverty and vulnerability and improve consumption over time. The highest impacts of technologies are observed when these technologies are adopted jointly. We found that the use of combinations of chemical fertilizer, improved seed variety, pesticide and SWC practices lead to higher levels of real per capita consumption. The ordered probit marginal effects estimates also supported the counterfactual analysis and show that agricultural technologies are crucial to reducing poverty.

Based on our findings, we conclude that the adoption of PETs and SWC measures are very helpful in improving the welfare of adopters irrespective of their poverty status (chronically poor, vulnerable, or non-poor). We, therefore, suggest that much more intervention is warranted to ensure that the chronically poor and vulnerable farm households can have access to improved agricultural technology.

Acknowledgements We thank the Deutsche Forschungsgemeinschaft (DFG) and the Deutscher Akademischer Austauschdienst (DAAD) for funding this research project, and two anonymous reviewers for their helpful comments. We are also grateful to the International Food Policy Research Institute (IFPRI) in Addis Ababa for providing us the sample households with the baseline data.

Open Access This article is distributed under the terms of the Creative Commons Attribution 4.0 International License (http://creativecommons.org/licenses/by/4.0/), which permits use, duplication, adaptation, distribution and reproduction in any medium or format, as long as you give appropriate credit to the original author(s) and the source, provide a link to the Creative Commons license and indicate if changes were made.

\section{Appendix}

See Table 8. 


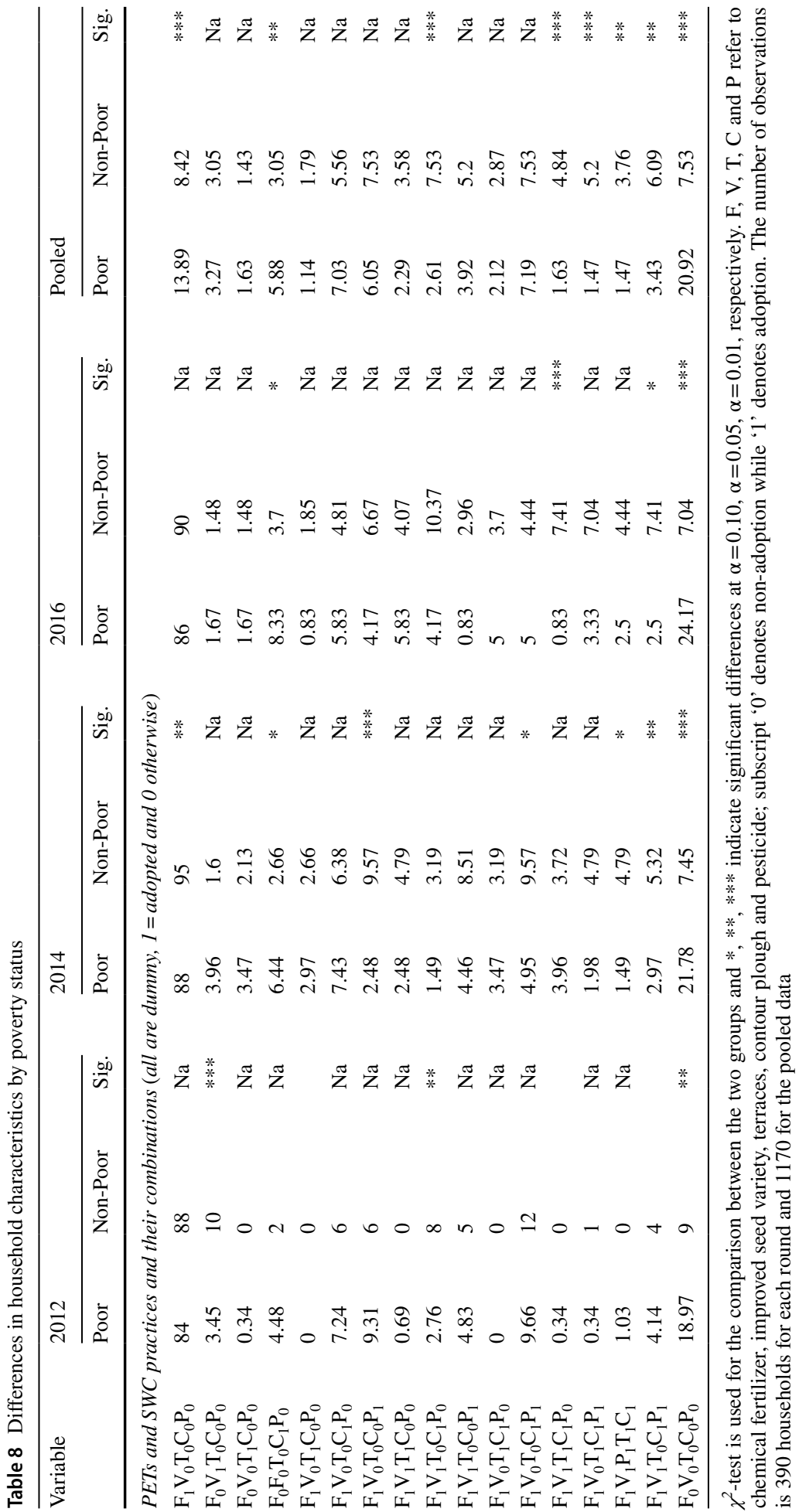




\section{References}

Abdulai, A., \& Huffman, W. (2014). The adoption and impact of soil and water conservation technology: An endogenous switching regression application. Land Economics, 90(1), 26-43.

Abebe, Z. D., \& Sewnet, M. A. (2014). Adoption of soil conservation practices in North Achefer District, Northwest Ethiopia. Chinese Journal of Population Resources and Environment, 12(3), 261-268.

Ali, A., \& Abdulai, A. (2010). The adoption of genetically modified cotton and poverty reduction in Pakistan. Journal of Agricultural Economics, 61(1), 175-192.

Alwang, J., Siegel, P. B., \& Jorgensen, S. (2001). Vulnerability: A view from different disciplines (No. 0115). Washington DC: World Bank.

Asfaw, D., \& Neka, M. (2017). Factors affecting adoption of soil and water conservation practices: The case of Wereillu Woreda (District), South Wollo Zone, Amhara Region, Ethiopia. International Soil and Water Conservation Research, 5(4), 273-279.

Asfaw, S., Shiferaw, B., Simtowe, F., \& Hagos, M. (2011). Agricultural technology adoption, seed access constraints and commercialization in Ethiopia. Journal of Development and Agricultural Economics, 3(9), 436-447.

Asfaw, S., Shiferaw, B., Simtowe, F., \& Lipper, L. (2012). Impact of modern agricultural technologies on smallholder welfare: Evidence from Tanzania and Ethiopia. Food Policy, 37(3), 283-295.

Baker, J. L. (2000). Evaluating the impact of development projects on poverty: A handbook for practitioners. Washington DC: The World Bank.

Becerril, J., \& Abdulai, A. (2009). The impact of improved maize varieties on poverty in Mexico: A propensity score-matching approach. World Development, 38(7), 1024-1035.

Beegle, K., Christiaensen, L., Dabalen, A., \& Gaddis, I. (2016). Poverty in a rising Africa. Washington, DC: The World Bank.

Bezu, S., Kassie, G. T., Shiferaw, B., \& Ricker-Gilbert, J. (2014). Impact of improved maize adoption on welfare of farm households in Malawi: A panel data analysis. World Development, 59, 120-131.

Christiaensen, L. J., \& Subbarao, K. (2005). Towards an understanding of household vulnerability in rural Kenya. Journal of african economies, 14(4), 520-558.

de Janvry, A., Fafchamps, M., \& Sadoulet, E. (1991). Peasant household behaviour with missing markets: Some paradoxes explained. Economic \& Political Weekely, 101(409), 1400-1417.

de Janvry, A., \& Sadoulet, E. (2002). World poverty and the role of agricultural technology: Direct and indirect effects. Journal of Development Studies, 38(4), 1-26.

Demeke, A. B., Keil, A., \& Zeller, M. (2011). Using panel data to estimate the effect of rainfall shocks on smallholders food security and vulnerability in rural Ethiopia. Climatic Change, 108(1-2), 185-206.

Dercon, S. (2004). Growth and shocks: Evidence from rural Ethiopia. Journal of Development Economics, 74(2), 309-329.

Dercon, S., Gilligan, D. O., Hoddinott, J., \& Woldehanna, T. (2009). The impact of agricultural extension and roads on poverty and consumption growth in fifteen Ethiopian Villages. American Journal of Agricultural Economics, 91(4), 1007-1021.

Dercon, S., Hoddinott, J., \& Woldehanna, T. (2005). Shocks and consumption in 15 Ethiopian villages, 1999-2004. Journal of African Economies, 14(4), 559-585.

Di Falco, S., \& Bulte, E. (2013). The impact of kinship networks on the adoption of risk-mitigating strategies in Ethiopia. World Development, 43, 100-110.

Di Falco, S., Yesuf, M., Kohlin, G., \& Ringler, C. (2011). Estimating the impact of climate change on agriculture in low-income countries: Household level evidence from the Nile Basin, Ethiopia. Environmental and Resource Economics, 52(4), 457-478.

Diao, X. (2010). Economic importance of agriculture for sustainable development and poverty reduction: The case study of Ethiopia. Global Forum on agriculture: Policies for agricultural development, poverty reduction and food security. http://www.oecd.org/agriculture/agricultural-policies/46378942.pdf. Accessed 21 Dec 2019.

Doss, C., Mwangi, W., Verkuijl, H., \& Groote, H. De. (2003). Adoption of maize and wheat technologies in Eastern Africa: A synthesis of the findings of 22 case studies (No. 3-6). CIMMYT: Mexico, D.F.

Dubin, J. A., \& Mcfadden, D. L. (1984). An econometric analysis of residential electric appliance holdings and consumption. Econ, 52(2), 345-362.

Foster, J., Joel, G., \& Eric, T. (1984). A class of decomposable poverty measures. Econometrica, 52(3), 761-766.

Gregory, C. A. (2015). Estimating treatment effects for ordered outcomes using maximum simulated likelihood Christian. The Stata Journal, 15(3), 756-774. 
Hailu, B. K., Abrha, B. K., \& Weldegiorgis, K. A. (2014). Adoption and impact of agricultural technologies on farm income: Evidence from Southern Tigray, Northern Ethiopia. International Journal of Food and Agricultural Economics, 2(4), 91-106.

Haughton, J., \& Khandker, S. R. (2009). Handbook on poverty and inequality. Washington, DC: The World Bank.

Hausman, J. A. (1978). Specification tests in econometrics. Econometrica, 46(46), 1251-1271.

Heckman, J. (1979). Sample selection bias as a specification. Econometrica, 47(1), 153-161.

Hoddinott, J., \& Quisumbing, A. (2003). Methods for microeconometric risk and vulnerability assessment: Social protection discussion paper series. Report No. 0324. The World Bank.

Hoddinott, J., \& Quisumbing, A. (2010). Methods for microeconometric risk and vulnerability assesment. In: R. Fuentes-Nieva \& P. A. Seck (Eds.) Risk,Shocks, and Human Development. London: Palgrave Macmillan.

Howard, J., Crawford, E., Kelly, V., Demeke, M., \& Jeje, J. J. (2003). Promoting high-input maize technologies in Africa: The Sasakawa-Global 2000 experience in Ethiopia and Mozambique. Food Policy, 28(4), 335-348.

Kassie, M., Jaleta, M., Shiferaw, B., Mmbando, F., \& Mekuria, M. (2013). Adoption of interrelated sustainable agricultural practices in smallholder systems: Evidence from rural Tanzania. Technological Forecasting and Social Change, 80(3), 525-540.

Kassie, M., Marenya, P., Tessema, Y., Jaleta, M., Zeng, D., Erenstein, O., et al. (2018). Measuring farm and market level economic impacts of improved maize production technologies in Ethiopia: Evidence from panel data. Journal of Agricultural Economics, 69(1), 76-95.

Kassie, M., Teklewold, H., Marenya, P., Jaleta, M., \& Erenstein, O. (2015). Production risks and food security under alternative technology choices in Malawi: Application of a multinomial endogenous switching regression. Journal of Agricultural Economics, 66(3), 640-659.

Long, J. S., \& Freese, J. (2014). Regression models for categorical dependent variables using stata (3rd ed.). College Station, Texas: Stata Press.

Maddala, G. (1983). Limited-dependent and qualitative variables in economics. New York: Cambridge University Press.

Manda, J., Alene, A. D., Gardebroek, C., Kassie, M., \& Tembo, G. (2016). Adoption and impacts of sustainable agricultural practices on maize yields and incomes: Evidence from rural Zambia. Journal of Agricultural Economics, 67(1), 130-153.

Mandefro, N., Mohammed, H., Sebokssa, G., Bogale, G., Beyene, Y., S, H., \& Aderajew, H. (2002). Maize improvement for drought stressed areas of Ethiopia. In Proceedings of the second national maize workshop of Ethiopia (pp. 15-26). Addis Ababa, Ethiopia: Central Printing Press.

Mango, N., Makate, C., Tamene, L., Mponela, P., \& Ndengu, G. (2017). Awareness and adoption of land, soil and water conservation practices in the Chinyanja Triangle, Southern Africa. International Soil and Water Conservation Research, 5(2), 122-129.

Minot, N., \& Sawyer, B. (2013). Agricultural production in Ethiopia: Results of the 2012 ATA baseline survey. Resource document. http://ebrary.ifpri.org/cdm/ref/collection/p15738coll2/id/127950. Accessed 13 September 2017.

Misiko, M., \& Ramisch, J. (2007). Integrated soil fertility management technologies:review for scaling up. In A. Bationo (Ed.), Advances in integrated soil fertility management in Sub-saharan Africa: Challenges and opportunities. Dordrecht: Springer.

MoFED (Ministry of Finance and Economic Development). (2003). Rural development Policy and strategies. Resource document. Ministry of finance and economic development. http://gafspfund.org/sites/ gafspfund.org/files/Documents/Ethiopia_4_of_6_ARD policy.pdf. Accessed 27 September 2017.

Morris, M. L., \& Doss, C. R. (1999). How does gender affect the adoption of agricultural innovations? The case of improved maize technology in Ghana. American Agricultural Economics Association, 25, 27-39.

Moser, C. O. N. (1998). The asset vulnerability framework: Reassessing urban poverty reduction strategies. World Development, 26(1), 1-19.

Mundlak, Y. (1978). On the pooling of time series and cross section data. Econometrica, 46(1), 69-85.

Pender, J., Place, F., \& Ehui, S. (2006). Strategies for sustainable land management in the East African highlands. International Food Policy Research Institute. https://doi.org/10.2499/0896297578.

Sharma, M., Zeller, M., Henry, C., Lapenu, C., \& Helms, B. (2000). Assessing the relative poverty level of MFI clients: synthesis report based on four case studies. Food Policy. https://www.cgap.org/sites/defau 1t/files/CGAP-Technical-Guide-Assessing-the-Relative-Poverty-Level-of-MFI-Clients-Case-StudiesJun-2000.pdf. Accessed 12 Oct 2018.

Spielman, D. J., Byerlee, D., Alemu, D., \& Kelemework, D. (2010). Policies to promote cereal intensification in Ethiopia: The search for appropriate public and private roles. Food Policy, 35(3), 185-194. 
Spielman, D., Kelemwork, D., \& Alemu, D. (2011). Seed, fertilizer and agricultural extension in Ethiopia. ESSP II working paper 020 International Food Policy Research Institute.

Spielman, D. J., Alemu, D., \& Mekonnen, D. K. (2012). Seed, fertilizer, and agricultural extension in Ethiopia. In P. Dorosh \& S. Rashid (Eds.), Food andagriculture in ethiopia: progress and policy challenges (pp. 84-122). Philadelphia: University of Pennsylvania Press.

Tadesse, M., \& Degu, G. (2002). Review of on-farm research and adoption studies on maize in Southern Ethiopia. In M. Nigussie, D. Tanner, \& S. Twumasi-Afriyie (Eds.), Proceedings of the second national maize workshop of Ethiopia (pp. 137-143). Addis Ababa: Central Printing Press.

Teklewold, H., Kassie, M., Shiferaw, B., \& Köhlin, G. (2013). Cropping system diversification, conservation tillage and modern seed adoption in Ethiopia: Impacts on household income, agrochemical use and demand for labor. Ecological Economics, 93, 85-93.

Verkaart, S., Munyua, B. G., Mausch, K., \& Michler, J. D. (2017). Welfare impacts of improved chickpea adoption: A pathway for rural development in Ethiopia? Food Policy, 66, 50-61.

Wolka, K. (2014). Effect of soil and water conservation measures and challenges for its adoption: Ethiopia in focus. Journal of Environmental Science and Technology, 7(4), 185-199.

Wooldridge, J. M. (2002). Econometric analysis of cross section and panel data. London: MIT Press.

World Bank. (2005). Well-being and poverty in Ethiopia: The role of agriculture and agency. Document of the World Bank. Report No. 29468-ET.

World Bank. (2015). Ethiopia poverty assessment: Poverty global practice-Africa region. Document of the World Bank. Report No. AUs6744.

Wozniak, G. D. (1984). The adoption of interrelated innovations: A human capital approach. The MIT Press, 66(2), 296-303.

Yu, B., \& Nin-Pratt, A. (2014). Fertilizer adoption in Ethiopia cereal production. Journal of Development and Agricultural Economics, 6(7), 318-337.

Zeng, D., Alwang, J., Norton, G. W., Shiferaw, B., Jaleta, M., \& Yirga, C. (2015). Ex post impacts of improved maize varieties on poverty in rural Ethiopia. Agricultural Economics, 46(4), 515-526.

Publisher's Note Springer Nature remains neutral with regard to jurisdictional claims in published maps and institutional affiliations. 